\title{
Current-Controlled Current-Mode Quadrature Oscillator Using Translinear Current Conveyors
}

\author{
Montree Kumngern ${ }^{1}$
}

\begin{abstract}
In this paper, a current-mode quadrature oscillator using second-generation current conveyors (CCIIs) is presented. The proposed oscillator consists of two CCIIs, two grounded capacitors and two grounded resistors. The circuit is suitable for integrated circuit implementation by using grounded capacitors. In addition, a new current-controlled current-mode quadrature oscillator using two current controlled second generation current conveyors (CCCIIs) and two grounded capacitors can be obtained by replacing CCIIs and resistors series at $\mathrm{X}$ terminals with CCCIIs. The condition of oscillation and frequency of oscillation can be orthogonally controlled. The frequency of oscillation can be controlled by grounded resistors and external bias currents. The proposed circuits have been simulated by SPICE simulations. The simulation results are confirmed the proposed theory.
\end{abstract}

Keywords -All-pass section, quadrature oscillator, current-mode circuit, second gerenation current conveyor (CCII), CCCII.

\section{INTRODUCTION}

Quadrature oscillator typically provides two sinusoids with $90^{\circ}$ phase difference for a variety of applications such as in telecommunications for quadrature mixers, single-sideband generators, direct-conversion receivers, or in measurement purposes for vector generators and for selective voltmeters [1], [2]. Over the years, many schemes of voltage-mode and current-mode quadrature oscillators have been presented, for instance, see [3]-[18]. The structures in [3]-[8] are suitable for monolithic integrated circuit (IC) implementation by using grounded capacitors. On the other hand, current-mode oscillators with high-output current sources are of great interest because these output current sources can be directly connected to loads without using buffer circuits [12]-[15]. Several current-mode quadrature oscillators have been proposed base on different techniques. In [8]-[11], the currentmode quadrature oscillators using single active device are proposed but the circuits suffer from several disadvantages such as complexity, employment a large number of grounded or floating passive devices and low-output impedance level. In 2002 and 2003, two quadrature oscillator circuits using two current differencing buffered amplifiers (CDBAs) [12] and two differential voltage current conveyors (DVCCs) [13] with two grounded capacitors and two grounded resistors have been proposed. In 2006, two quadrature oscillator circuits using a fully-differential second-generation current conveyor (FDCCII) with two grounded capacitors and two (or three)

${ }^{1}$ Lecturer, Department of Telecommunications Engineering, Faculty of Engineering, King Mongkut's Institute of Technology Ladkrabang, Bangkok 10250, THAILAND (e-mail: kkmontre@gmail.com) grounded resistors have been introduced by [14]. The currentmode quadrature oscillator using two current differencing transconductance amplifiers (CDTAs), two floating capacitors and four floating resistors is proposed [15]. The circuits in [12]-[15] provide high-output impedance current sources. However, all structures lack electronic tuning capability. Moreover, the current-mode oscillator circuit in [15] employs floating passive devices.

Recently, current-controlled oscillators based on translinear current conveyors (CCCII) [18] has been interested because the parameter frequency of oscillator can be varied by external bias current. This property makes it different from current conveyor-based oscillators [13]-[14], [16]. By applying high bias current to CCCII, CCCII can be operared as conventional second-generation current conveyor (CCII) (neglecting resistance at $\mathrm{X}$-terminal). The quadrature oscillators using CCCII as active device are reported in [17], [18]. However, the circuits suffer from the use of excessive number of active components (four CCCIIs in [17], three CCCIIs in [18]). Also, the realization of quadrature oscillator in [18] suffers from the use of floating capacitor.

In this paper, a current-mode quadrature oscillator using two CCIIs, two grounded capacitors and two grounded resistors is presented. The circuit provides the advantage of using grounded capacitors that are beneficial to IC implementation. Furthermore, from the proposed CCII-based quadrature oscillator, by replacing CCII and resistors connected series at X-terminal by CCCIIs, a new currentcontrolled quadrature oscillator using only two CCCIIs and two grounded capacitors can be obtained. The circuits provide two high-output impedance current sources with $90^{\circ}$ phase difference. The new topology are not found in open literature. The circuits are higher suitable for IC implementation when compared with the oscillator circuits in [3]-[18].

\section{PROposed CIRCUIT}

Fig. 1 and Fig. 2 show the basic building blocks of the proposed current-mode quadrature oscillator circuit. Each circuit consists of a CCII, a grounded capacitor and a grounded resistor. The multiple-output CCII can be obtained by modifying from conventional CCII [19] by adding additional current-mirrors and cross-coupled current mirrors to obtain plus- and minus-type outputs [20]. The standard notations of CCII can be characterized by $V_{X}=V_{Y}, I_{Z}= \pm I_{X}$ and $I_{Y}=0$. Using this relation and nodal analysis, the transfer functions of circuits in Fig. 1 and Fig. 2 can be respectively expressed as

$$
\frac{I_{\text {out }}}{I_{\text {in }}}=\frac{s C_{1} R_{1}-1}{s C_{1} R_{1}+1}
$$




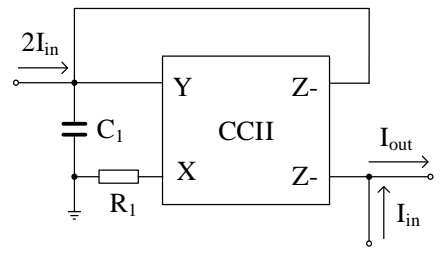

Fig. 1 Current-mode all-pass section.

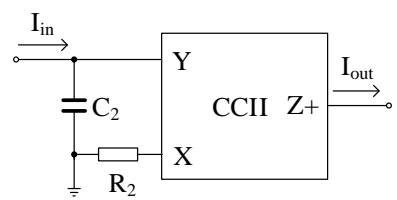

Fig. 2 Current-mode lossless integrator.

$$
\frac{I_{\text {out }}}{I_{\text {in }}}=\frac{1}{S C_{2} R_{2}} \text {. }
$$

From (1) and (2), it should be noted that Fig. 1 is the allpass section and Fig. 2 is the lossles integrator circuit. According to [21], the quadrature oscillator can be realized using an all-pass section and a lossless integrator. By using the all-pass section and lossless integrator circuits in Fig. 1 and Fig. 2, the proposed quadrature oscillator can be shown in Fig. 3. The structure is cascaded by all-pass filter circuit in Fig. 1, lossless integrator in Fig. 2 and feedback connection. The characteristic equation of Fig. 3 can be expressed by

$$
s^{2} C_{1} C_{2} R_{1} R_{2}+s\left(C_{2} R_{2}-C_{1} R_{1}\right)+1=0 .
$$

Letting $R_{1}=R_{2}=R$, the condition of oscillation and frequency of oscillation can be obtained respectively as

$$
C_{1} \geq C_{2}
$$

and

$$
\omega_{o}=\frac{1}{R \sqrt{C_{1} C_{2}}} .
$$

It is evident from (4) and (5), that the condition of oscillation can be adjusted by grounded capacitors $C_{1}$ and $C_{2}$ and the frequency of oscillation can be controlled by varying the grounded resistors $R$ (i.e. $R_{1}=R_{2}=R$ ) without disturbing the condition of oscillation. From the circuit in Fig. 3, $\mathrm{CCII}_{2}$ along with $C_{2}$ and $R_{2}$ form of the lossless integrator, the relationship between output currents $I_{\text {out } 1}$ and $I_{\text {out2 } 2}$ can be expressed as

$$
\frac{I_{\text {out } 2}}{I_{\text {out } 1}}=\frac{1}{s C_{2} R_{2}}
$$

where the phase shift is $\phi=\pi / 2$, which quarantees that proposed oscillator circuit provides the quadrature output

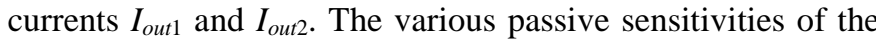
parameter $\omega_{\mathrm{o}}$ with the passive devices are

$$
S_{C_{1}}^{\omega_{0}}=S_{C_{2}}^{\omega_{0}}=S_{R_{1}}^{\omega_{0}}=S_{R_{2}}^{\omega_{0}}=-\frac{1}{2}
$$

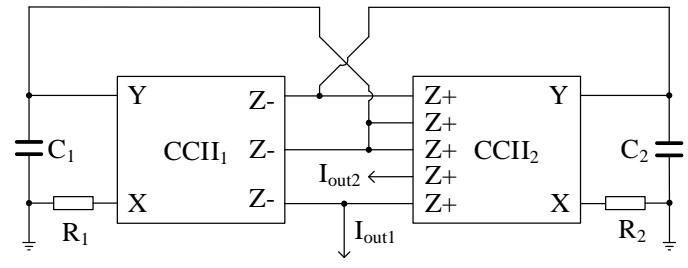

Fig. 3 Proposed CCII-based quadrature oscillator.

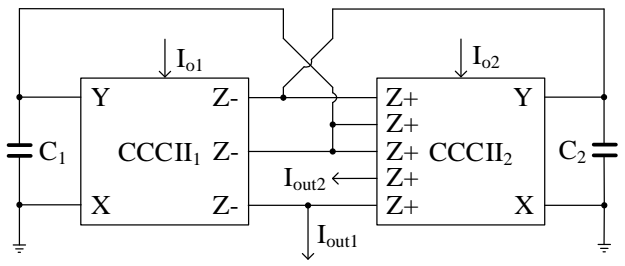

Fig. 4 Proposed CCCII-based quadrature oscillator.

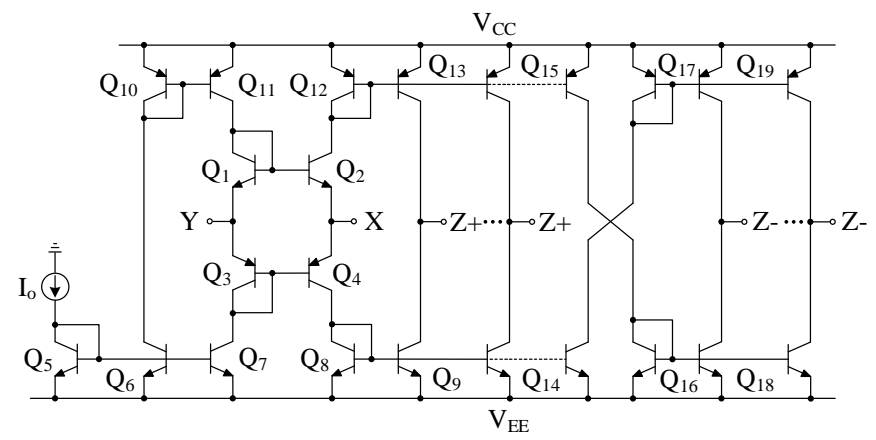

Fig. 5 Schematic implementation for CCCII [20].

Because the outputs $I_{\text {out } 1}$ and $I_{\text {out } 2}$ in Fig. 3 are the zterminals of CCIIs which typically provide high-impedance level, hence the outputs $I_{\text {out } 1}$ and $I_{\text {out } 2}$ also possesses highimpedance level which can be directly connected to the loads.

The CCCII can be designed based on translinear elements and current mirrors [22]. The circuit has a finite resistance at X-terminal $\left(R_{X}\right)$, where $R_{X}=V_{T} / 2 I_{o}, I_{o}$ is the bias current and $V_{T}$ is the thermal voltage $\left(V_{T} \cong 26 \mathrm{mV}\right.$ at $\left.27^{\circ} \mathrm{C}\right)$. Thus, CCCII will provide $R_{X}$ at $\mathrm{X}$-terminal that can be tuned by bias current $I_{o}$. From Fig 3, if CCIIs with resistors at the X-terminal are replaced by CCCIIs, a new CCCII-based quadrature oscillator can be obtained as shown in Fig. 4. The CCCII-based quadrature oscillator employs only two CCCIIs and two grounded capacitors. The characteristic equation of Fig. 4 can be expressed by

$$
s^{2} C_{1} C_{2} R_{X 1} R_{X 2}+s\left(C_{2} R_{X 2}-C_{1} R_{X 1}\right)+1=0
$$

or

$$
s^{2} C_{1} C_{2} V_{T}^{2}+s 2 V_{T}\left(C_{2} I_{o 1}-C_{1} I_{o 2}\right)+4 I_{o 1} I_{o 2}=0 .
$$

Letting $I_{o 1}=I_{02}=I_{o}$, the condition of oscillation and frequency of oscillation can be expressed respectively as

$$
C_{1} \geq C_{2}
$$

and 


$$
\omega_{o}=\frac{2 I_{o}}{V_{T} \sqrt{C_{1} C_{2}}} .
$$

The condition of oscillation of Fig. 4 can be controlled by grounded capacitor $C_{1}$ and $C_{2}$ and frequency of oscillation can be controlled by varying the bias currents $I_{o}$ (i.e. $I_{o}=I_{o 1}=I_{o 2}$ ). This implies that the circuit in Fig. 4 can be worked as current-controlled oscillator.

\section{NON-IDEAL EFFECTS}

Taking the non-idealities of the CCII into account, the relations of voltage and current characteristics can be expressed as

$$
\left(\begin{array}{c}
I_{Y} \\
V_{X} \\
I_{Z}
\end{array}\right)=\left(\begin{array}{ccc}
0 & 0 & 0 \\
\alpha & 0 & 0 \\
0 & \pm \beta & 0
\end{array}\right)\left(\begin{array}{c}
V_{Y} \\
I_{X} \\
V_{Z}
\end{array}\right)
$$

where $\alpha=1-\varepsilon,|\varepsilon| \ll 1$ represents the voltage tracking error, $\beta=$ $1-\delta,|\delta| \ll 1$ represents the current tracking error. Using (12), the transfer function of Fig. 1 becomes

$$
\frac{I_{\text {out }}}{I_{\text {in }}}=\frac{s C_{1} R_{1}+1-2 \beta_{1}}{s C_{1} R_{1}+1}
$$

where $\beta_{1}$ is the current gain error between $\mathrm{z}$ - and $\mathrm{x}$-terminal of CCII1. Using (12), the transfer function of Fig. 2 becomes

$$
\frac{I_{\text {out }}}{I_{\text {in }}}=\frac{\alpha_{2} \beta_{2}}{s C_{2} R_{2}} \text {. }
$$

Therefore, the characteristic equation of Fig. 3 becomes

$$
\begin{aligned}
& s^{2} C_{1} C_{2} R_{1} R_{2}+s\left(C_{2} R_{2}-\beta_{2}^{2} \alpha_{2} C_{1} R_{1}\right) . \\
& +\left(2 \alpha_{2} \beta_{1} \beta_{2}^{2}-\alpha_{2} \beta_{2}^{2}\right)=0
\end{aligned}
$$

The modified condition of oscillation and frequency of oscillation are

$$
\beta_{2}^{2} \alpha_{2} C_{1} \geq C_{2}
$$

and

$$
\omega_{o}=\frac{1}{R} \sqrt{\frac{2 \alpha_{2} \beta_{1} \beta_{2}^{2}-\alpha_{2} \beta_{2}^{2}}{C_{1} C_{2}}}
$$

where $R=R_{1}=R_{2}$. From (16) and (17), the voltage and current errors slightly change the condition of oscillation and frequency of oscillation. However, the condition of oscillation and frequency of oscillation can be orthogonally controlled. The active and passive sensitivities of $\omega_{0}$ are analysed and found within 0.5 in magnitude which express good sensitivity performance of the circuit.

\section{Simulation Results}

The proposed circuits were simulated using SPICE simulations. The current conveyor in Fig. 5 [20] was performed with the transistor model of NR100N and PR100N of the bipolar arrays ALA400 from AT\&T [23] as listed in Table I. The voltage supply was taken as $V_{C C}=3 \mathrm{~V}, V_{E E}=-3$ V. By taking high bias current $I_{o}$, CCCII in Fig. 5 can be worked as CCII ( $R_{X}$ is negleged). To achieve the CCII, the circuit in Fig. 5 was biased with $I_{o}=250 \mu \mathrm{A}\left(R_{X} \approx 50 \Omega\right)$. The proposed quadrature oscillator Fig. 3 was designed with $R_{1}=$ $R_{2}=1 \mathrm{k} \Omega, C_{1}=12 \mathrm{nF}$, and $C_{2}=10 \mathrm{nF}$, where $C_{1}$ was designed to be larger than $C_{2}$ to ensure the oscillator will start. The condition $R_{1}, R_{2}$ » $R_{X}$ should be used to avoid the effect of parasitic resistance $R_{X}$. These passive-values were used to design the frequency of oscillation of $14.52 \mathrm{kHz}$.

TABLE I

MODEL PARAMETERS OF NR200N AND PR200N TRANSISTORS

*NR200N-2X NPN TRANSISTOR
.MODEL NX2 NPN RB $=262.5$ IRB $=0$ RBM $=12.5$ RC $=25$

$\mathrm{RE}=0.5 \mathrm{IS}=242 \mathrm{E}-18 \mathrm{EG}=1.206 \mathrm{XTI}=2 \mathrm{XTB}=1.538 \mathrm{BF}=137.5$

$\mathrm{IKF}=13.94 \mathrm{E}-3 \mathrm{NF}=1 \mathrm{VAF}=159.4 \mathrm{ISE}=72 \mathrm{E}-16 \mathrm{NE}=1.713$

$\mathrm{BR}=0.7258 \mathrm{IKR}=4.396 \mathrm{E}-3 \mathrm{NR}=1 \mathrm{VAR}=10.73 \mathrm{ISC}=0 \mathrm{NC}=2$

$\mathrm{TF}=0.425 \mathrm{E}-9 \mathrm{TR}=0.425 \mathrm{E}-8 \mathrm{CJE}=0.428 \mathrm{E}-12 \mathrm{VJE}=0.5$

$\mathrm{MJE}=0.28 \mathrm{CJC}=1.97 \mathrm{E}-13 \mathrm{VJC}=0.5 \mathrm{MJC}=0.3 \mathrm{XCJC}=0.065$

$\mathrm{CJS}=1.17 \mathrm{E}-12 \mathrm{VJS}=0.64 \mathrm{MJS}=0.4 \mathrm{FC}=0.5$

$*$ PR200N-2X PNP TRANSISTOR

.MODEL PX2 NPN RB=163.5 IRB=0 RBM=12.27 RC=25

$\mathrm{RE}=1.5 \mathrm{IS}=147 \mathrm{E}-18 \mathrm{EG}=1.206 \mathrm{XTI}=1.7 \mathrm{XTB}=1.866$

$\mathrm{BF}=110.0 \mathrm{IKF}=4.718 \mathrm{E}-3 \mathrm{NF}=1 \mathrm{VAF}=51.8 \mathrm{ISE}=50.2 \mathrm{E}-16$

$\mathrm{NE}=1.65 \mathrm{BR}=0.4745 \mathrm{IKR}=12.96 \mathrm{E}-3 \mathrm{NR}=1 \mathrm{VAR}=9.96 \mathrm{ISC}=0$

$\mathrm{NC}=2 \mathrm{TF}=0.610 \mathrm{E}-9 \mathrm{TR}=0.610 \mathrm{E}-8 \mathrm{CJE}=0.36 \mathrm{E}-12 \mathrm{VJE}=0.5$

$\mathrm{MJE}=0.28 \mathrm{CJC}=0.328 \mathrm{E}-12 \mathrm{VJC}=0.8 \mathrm{MJC}=0.4 \mathrm{XCJC}=0.074$

$\mathrm{CJS}=1.39 \mathrm{E}-12 \mathrm{VJS}=0.55 \mathrm{MJS}=0.35 \mathrm{FC}=0.5$

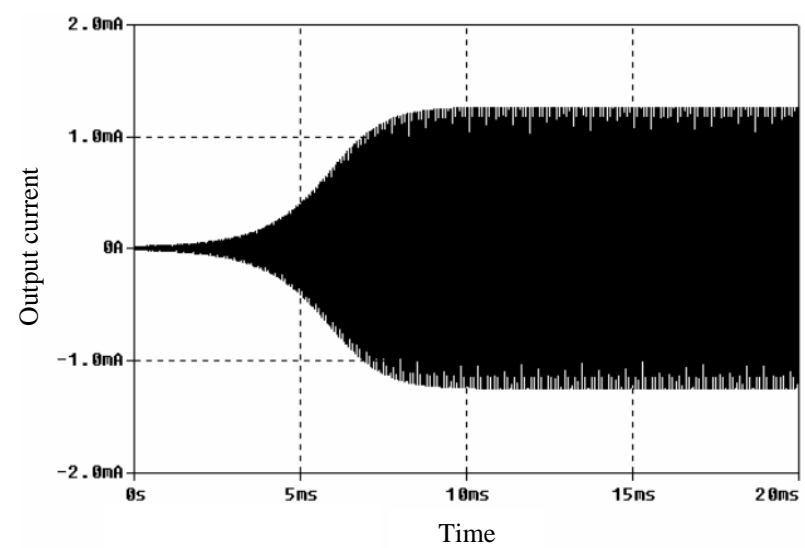

(a)

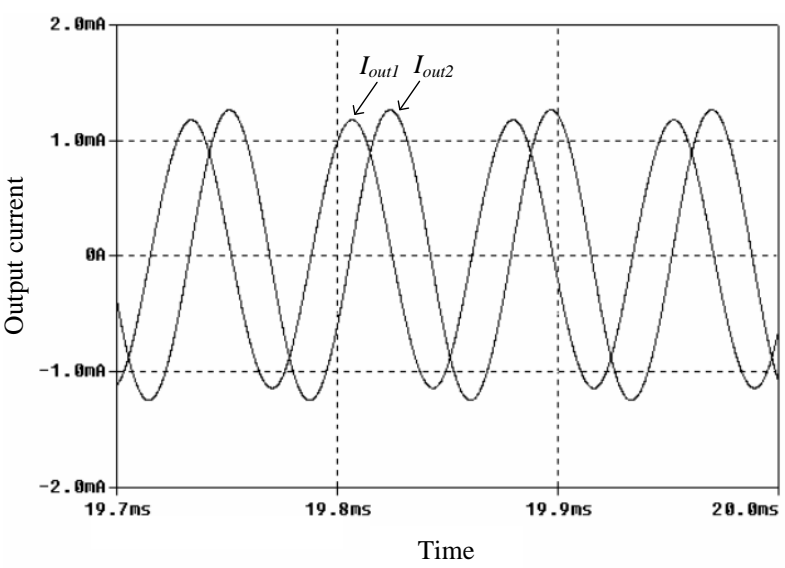

(b)

Fig. 6 The simulated output waveforms $I_{\text {out } 1}$ and $I_{\text {out } 2}$ of the proposed oscillator of Fig. 3, (a) at transient stage; (b) at steady stage. 


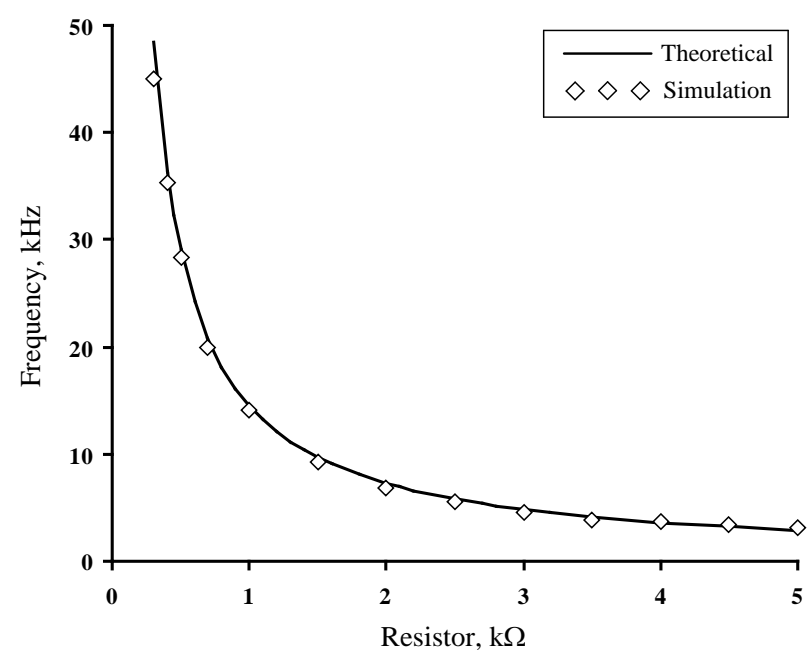

(a)

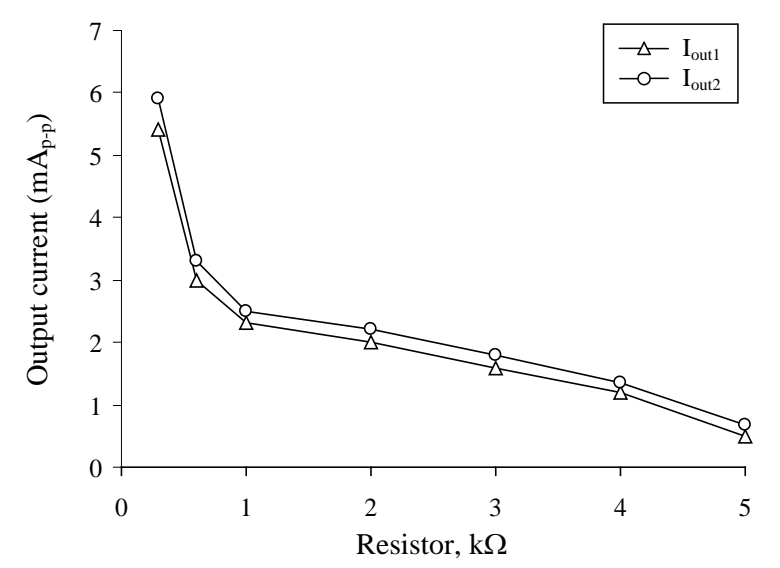

(b)

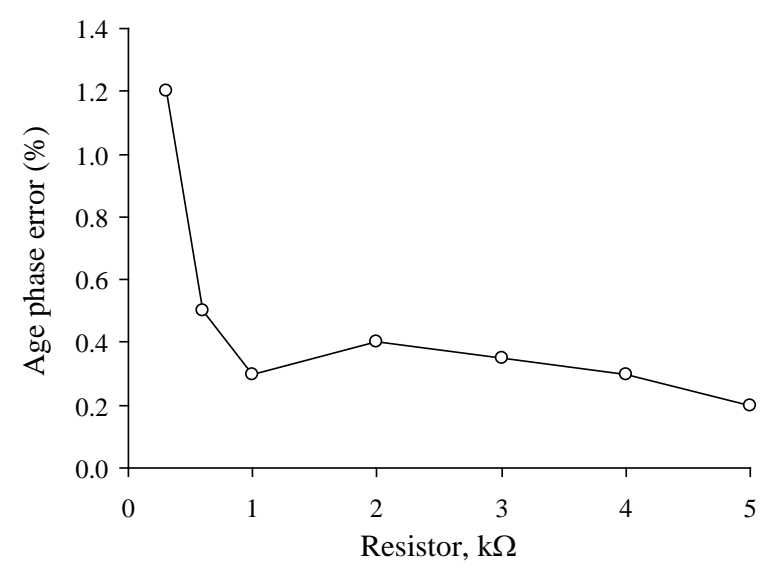

(c)

Fig. 7 Simulated results of the proposed circuit when the value of resistor $R\left(R=R_{1}=R_{2}\right)$ is varied: (a) the frequency of oscillation, (b) the amplitude of output currents, (c) the average of phase error.

Fig. 6(a) and Fig. 6(b) show the current output waveforms $\mathrm{I}_{\text {out1 }}$ and $\mathrm{I}_{\text {out2 }}$ of the proposed oscillator. From Fig. 6, simulated frequency of oscillation of $13.5 \mathrm{kHz}$ was expressed whereas the theoretical value was $14.52 \mathrm{kHz}$. The frequency of oscillation was $13.5 \mathrm{kHz}$ instead of $14.52 \mathrm{kHz}$ owing the

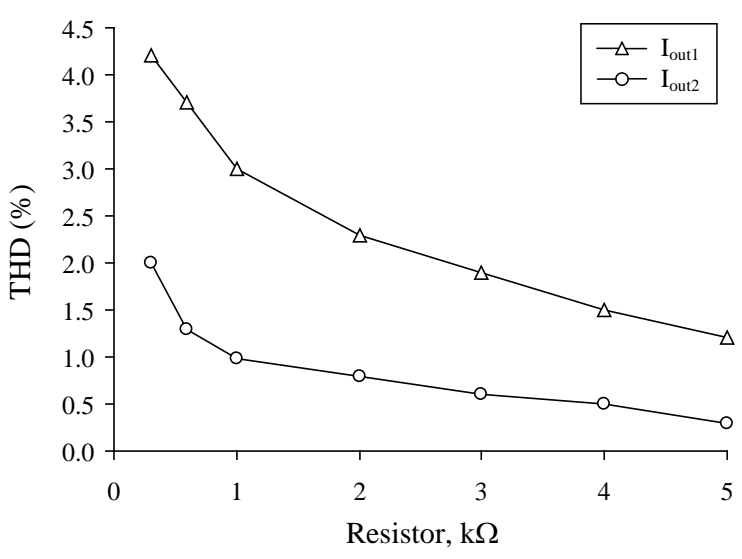

Fig. 8 Simulated total harmonic distortion of $I_{\text {out } 1}$ and $I_{\text {out } 2}$.

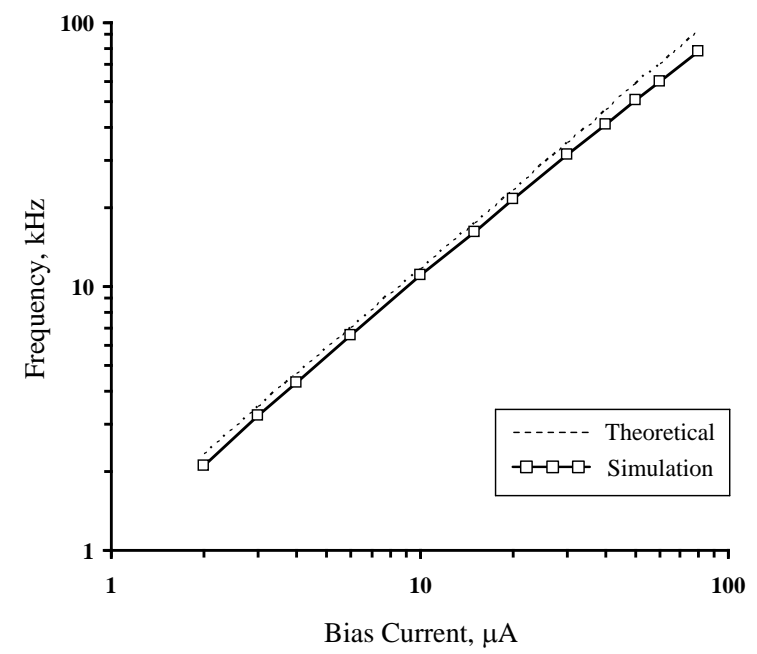

Fig. 9 Simulated the frequency of oscillation of Fig. 4 when the bias currents $I_{o}\left(I_{o}=I_{01}=I_{02}\right)$ was varied.

effect of non-ideal CCII. According to (17), this drop-off would be caused by voltage and current tracking errors of CCII. In practice, the value of the voltage and current tracking errors depend on the implementation scheme that is used to realize the CCCII, for example, $\beta \approx 0.999$ and $\alpha \approx 0.991$ for bipolar technology with the ALA200 transistor arrays [23]. Fig. 6(b), the $I_{\text {out } 1}$ and $I_{\text {out } 2}$ total harmonic distortions (THD) were $3 \%$ and $0.98 \%$, respectively. In this case, the power consumption was about $25 \mathrm{~mW}$. Fig. 7(a) shows the plot of the frequency of oscillation when the value of resistor $R$ was varied $\left(R=R_{2}=R_{2}\right)$ between $300 \Omega$ and $5 \mathrm{k} \Omega$. Note that if the resistors $R_{1}$ and $R_{2}$ are replaced by JFETs, the voltagecontrolled oscillator can be obtained [23]. Under the same condition in Fig. 7(a), the amplitude of output currents $I_{\text {out } 1}$ and $I_{\text {out2 }}$ was ploted as shown in Fig. 7(b) and average phase error between currents $I_{\text {out } 1}$ and $I_{\text {out } 2}$ that deviate from $90^{\circ}$ was ploted as shown in Fig. 7(c). The THD of currents $I_{\text {out } 1}$ and $I_{\text {out } 2}$ when the resistor $R$ was varied $\left(R=R_{2}=R_{2}\right)$ between 300 $\Omega$ and $5 \mathrm{k} \Omega$ was shown in Fig. 8 .

The proposed current-controlled quadrature oscillator in Fig. 4 was simulated. The circuit was tested using $V_{C C}=3 \mathrm{~V}$, $V_{E E}=-3 \mathrm{~V}$ voltage supply, $C_{1}=12 \mathrm{nF}$ and $C_{2}=10 \mathrm{nF}$. Because the operation of Fig. 4 is similar to Fig. 3, thus only 
the frequency of oscillation was investigated. Fig. 9 shows the simulated frequency of oscillation when the bias currents were varied between $2 \mu \mathrm{A}$ and $100 \mu \mathrm{A}$. The theoretical value was also included to compare. This result is confirmed (11).

\section{CONCLUSION}

In this paper, a new current-mode quadrature oscillator based on current conveyors is presented. The proposed circuit uses two CCIIs, two grounded capacitors and two grounded resistors. The proposed CCII-based quadrature oscillator can be modified to a current-controlled CCCII-based quadrature oscillator by replacing the CCIIs and resistor series at the $\mathrm{X}$ terminal with CCCIIs. The new current-controlled quadrature oscillator uses only two CCCIIs and two grounded capacitors. The circuit provides two high output impedance current sources with $90^{\circ}$ phase difference and the frequency of oscillation can be electronically controllable. The simulation results are agreeble with the theory. The proposed structure is suitable IC implementation and not found in open literature. Compared with quadrature oscillators in previous researches, the proposed oscillator employs equal active and passive elements, but the proposed oscillator provides electronic tuning capability. Compared with CCCII-based quadrature oscillators in previous researches, the proposed structure employs lesser active and passive components.

\section{REFERENCES}

[1] J.D. Gibson, The Communications Handbook, Boca Raton, USA: CRC Press, 1997.

[2] W. Bolton, Measurement and Instrumentation Systems, Oxford, UK: Butterworth-Heinemann, 1996.

[3] A. Rodriguez-Vazquez, B. Linares-Barranco, J.L. Huertas, and E. Sanchez-Sinencio, "On the Design of Voltage-Controlled Sinusoidal Oscillators Using OTA's,” IEEE Transactions on Circuits and Systems, Vol. 37, No. 2, pp. 198-211, 1990.

[4] P. Prommee and K. Dejhan, "An Integrable Electronic-Controlled Quadrature Sinusoidal Oscillator Using CMOS Operational Transconductance Amplifier," International Journal of Electronics, Vol. 89, No. 5, pp. 365-379, 2002.

[5] K. Kumwachara and W. Surakampontorn, "An Integrable TemperatureInsensitive gm-RC Quadrature Oscillator," International Journal of Electronics, Vol. 90, No. 9, pp. 599-605, 2003.

[6] J.W. Horng, C.L. Hou, C.M. Chang, W.Y. Chung, H.W. Tang, and Y.H. Wen, "Quadrature Oscillator using CCIIs," International Journal of Electronics, Vol. 92, No. 1, pp. 21-31, 2005.

[7] J.W. Horng, "Current Conveyors Based Allpass Filters and Quadrature Oscillators Employing Grounded Capacitors and Resistors," Computers and Electrical Engineering, Vol. 31, No. 1, pp. 81-92, 2005.

[8] M.T. Abuelma'atti, "Grounded Capacitor Current-Mode Oscillator Using Single Current Follower," IEEE Transactions on Circuits and Systems-I: Fundamental Theory and Applications, Vol. 39, No. 12, pp. 1018-1020, 1992.
[9] M.T. Abuelma'atti and H.A. Al-Zaher, "Current-Mode Sinusoidal Oscillators Using Single FTFN," IEEE Transactions on Circuits and Systems-II: Analog and Digital Signal Processing, Vol. 46, No. 1, pp. 69-74, 1999.

[10] S.I. Liu and Y.H. Liao, "Current-Mode Quadrature Sinusoidal Oscillator Using Single FTFN,” International Journal of Electronics, Vol. 81, No. 2, pp. 171-175, 1996.

[11] J.J. Chen, C.C. Chen, H.W. Tsao, and S.I. Liu, "Current-Mode Oscillators Using Single Current Follower," Electronics Letters, Vol. 27, No. 22, pp. 2056-2059, 1991.

[12] J.W. Horng, "Current Differencing Buffered Amplifiers Based Single Resistance Controlled Quadrature Oscillator Employing Grounded Capacitors," IEICE Transactions on Fundamentals of Electronics, Communications and Computer Sciences, Vol. E85-A, No. 6, pp. 14161419, 2002.

[13] J.W. Horng, "Current-Mode Quadrature Oscillator With Grounded Capacitors And Resistors Using Two DVCCs," IEICE Transactions on Fundamentals of Electronics, Communications and Computer Sciences, Vol.E86-A, No. 8, pp. 2152-2154, 2003.

[14] J.W. Horng, C.L. Hou, C.M. Chang, H.P. Chou, C T. Lin, and Y.H. Wen, "Quadrature Oscillators with Grounded Capacitors and Resistors Using FDCCIIs,” ETRI Journal, Vol. 28, No. 4, pp. 486-494, 2006.

[15] A.U. Keskin and D. Biolek, "Current Mode Quadrature Oscillator Using Current Differencing Transconductance Amplifier (CDTA)," IEE Proceeding of Circuits Devices and Systems, Vol. 153, No. 3, pp. 214218, 2006.

[16] M. Kumngern and K. Dejhan, "DDCC-Based Quadrature Oscillator with Grounded Capacitors and Resistors," Active and Passive Electronic Components, Vol. 2009, pp. 1-4, 2009.

[17] S. Maheshwari and I.A. Khan, "Current Controlled Third Order Quadrature Oscillator," IEE Proceeding of Circuits Devices and Systems, Vol. 152, No. 6, pp. 605-607, 2006.

[18] S. Maheshwari, "New Voltage and Current-Mode APS Using Current Controlled Conveyor," International Journal of Electronics, Vol. 91, No. 12, pp. 735-743, 2004.

[19] A. Fabre, O. Saaid, F. Wiest, and C Boucheron, "High Frequency Applications Based on a New Current Controlled Conveyor," IEEE Transactions on Circuits and Systems-I: Fundamental Theory and Applications, Vol. 43, No. 2, pp. 82-91, 1996.

[20] M.T. Abuelma'atti and M.A. Al-Qahtani, "A New Current-Controlled Multiphase Sinusoidal Oscillator Using Translinear Current Conveyor," IEEE Transactions on Circuits and Systems-II: Analog and Digital Signal Processing, Vol. 45, No. 7, pp. 881-885, 1998.

[21] M.T. Ahmed, I.A. Khan, and N. Minhaj, "On Transconductance-C Quadrature Oscillators,” International Journal of Electronics, Vol. 83, No. 2, pp. 201-207, 1997.

[22] A. Fabre, O. Saaid, F. Wiest, and C. Boucheron, "Current Controlled Bandpass Filter Based on Translinear Conveyors," Electronics Letters, Vol. 31, No. 20, pp. 1727-1728, 1995.

[23] D.R. Frey, "Log Domain Filtering: An Approach to Current Mode Filtering," IEE Proceedings of the Institute of Electrical Engineering, Part G, Circuits, Devices and Systems, Vol. 140, No. 6, pp. 406-416, 1993. 